\title{
Teaching Presence: Co-Creating a Multi-National Online Learning Community in an Asynchronous Classroom
}

\author{
Leanne M. Dzubinski, Ph.D \\ Cook School of Intercultural Studies \\ Biola University
}

\begin{abstract}
The pace of globalization coupled with the growing institutional pursuit of online education means online classes are increasingly composed of a multi-national, multi-ethnic, and multi-cultural student body. Teaching presence, which is the ability to structure the class, create the social environment, give instruction, and assess student work, is the basis for creating a community of inquiry in an online class where successful learning can occur. However, little is known about effective teaching presence in a multinational classroom. The purpose of this study was to examine my own efforts to co-create a social context in an online classroom environment that was welcoming and supportive to a diverse student population enrolled in a graduate research methods course. Findings show that building student confidence, affirming student voice, and the strategic use of groups can help create a climate of safety. Effective instructor techniques include setting the tone of the class through clear expectations, having ongoing public and private interaction with students, giving effective feedback, and recognizing and valuing cultural differences.
\end{abstract}

\section{INTRODUCTION}

In my first semester at a small, private West-Coast university, I was assigned to teach an online introductory research course in a graduate program. The 16 participants enrolled in the course came from five states, six countries, and represented multiple ethnicities. A number of students were multicultural in origin and in experiences, having been born in one country, raised in another, while working as adults in yet another. Similarly, a number of students married outside their original culture, and their ages ranged from 20 s to 60 s. In sum, they were a diverse group of students. As the course instructor, I was responsible for creating an effective online learning environment for all of them. I too am something of a multicultural person - though I was born and raised in the United States, I have lived and worked in Europe for almost 20 years. Therefore, the purpose of this study was to examine my own efforts to cocreate a social context in an online classroom that was welcoming and supportive to a diverse student population enrolled in a graduate research methods course. 


\section{THEORETICAL FRAMEWORK \& LITERATURE}

When facilitating an online class, I co-create a learning community with my students, both by the instructions I give and the by the expectations I explain and model through appropriate interaction and feedback (Cannon, 1990; Chick \& Hassel, 2009; Tollman, 2003). As a feminist educator, I desire to create a safe space composed of a respectful and inclusive learning environment (Chick \& Hassel, 2009). Each student is encouraged to have a voice, value is placed on personal experiences, and measures are implemented to ensure privileged voices do not dominate the conversation (Cannon, 1990). The online learning environment appears to support feminist pedagogy's value of diversity and inclusion through its ability to reach students who might otherwise not have access to education (Chick \& Hassel, 2009). It also appears to support feminist pedagogy's value of voice (Johnson-Bailey \& Lee, 2005) when it is structured so that all students are expected to post regularly in the discussion threads.

Further, the world of online teaching and learning has its own concept of space that must be created for learning to occur. Anderson, Rourke, Garrison, and Archer (2001) first framed the idea of "teaching presence" to describe three functions of the online instructor: designing and organizing the course, facilitating the social environment, and serving as subject-matter expert. They considered teaching presence to be one of three factors that create a community of inquiry online, the other two being cognitive and social presence in the classroom (Anderson, et al., 2001). In 2008, Akyol and Garrison conducted a follow-up study and found that the three elements of teaching presence were well defined and had not shifted since the earlier study. However, in 2010, Shea, Vickers \& Hayes reviewed the studies to date on teaching presence in the online classroom and suggested a slightly adjusted framework. They found that course design and organization, facilitated discourse, direct instruction, and assessment better reflected the concept of teaching presence in an online class (Shea, Vickers, \& Hayes, 2010). They adjusted facilitation of the social environment to facilitation of discourse because some studies found students could not distinguish between facilitating the environment and direct instruction (Shea, et al., 2010). Therefore, Shea and associates expanded the facilitation of social environment to include some of the instruction categories that revolved around approaches to content and called it facilitating discourse (Shea, et al., 2010). They also added a category of assessment, because teachers assess both participation and assignments, thereby making their presence known in the online classroom (Shea, et al., 2010).

The role of co-creating a social environment where learning can take place appears to be as vital to the success of an online class as it is in the traditional classroom. Because online interaction is entirely textbased without affordances such as visual, body-language, and tone of voice cues, the way social interaction is created becomes critical (Anderson, et al., 2001; Archer \& Garrison, 2010). A community of inquiry framework, which serves as the theoretical basis for a successful online classroom, relies heavily on collaborative relationships in the classroom (Akyol \& Garrison, 2008). The connection between feminist pedagogy's inclusive, respectful environment and online learning's emphasis on co-creating the social environment in which learning can occur is clear.

However, the role that culture and ethnicity play in creating the social environment is not well understood, since little research has been done on multinational classes (Morse, 2003). Online classes may be designed by instructors who know little about the cultures and ethnicities of their students (Rogers, Graham, \& Mayes, 2007). Western approaches and assumptions may not prove useful in teaching across cultures (Rogers, et al., 2007; Tollman, 2003). Western institutions and instructors might reflect "educational and cultural imperialism" (Sadykova \& Dautermann, 2009, p. 90), which is contrary to notions of a safe space. Yet given the current pace of globalization (Merriam, 2010) and the continuous movement towards international online education (Sadykova \& Dautermann, 2009), understanding how to create social context for learning in a multinational environment is of great significance to educators and institutions. Therefore, an online class consisting of students of multiple nationalities, ethnicities, races, professions, ages, and genders, is an ideal space to explore the intersection of teaching presence in social interaction and feminist concepts of respect and inclusion in the classroom as they relate to creating a virtual learning community. 


\section{RESEARCH DESIGN}

The majority of the research done to date on teaching presence in online courses has been quantitative (Shea, et al., 2010). In fact, Shea, Vickers, and Hayes, in their 2010 review of the literature, found only one study conducted solely using interviews. The majority of studies have been conducted by examining online discussion boards quantitatively, and analyzing instructor and student postings for content. Because the focus of this study was to evaluate the intersection of my deliberate attempts to create a social context, and the students' evaluation of their own ability to co-create and participate in that social context, qualitative research methods were chosen. Qualitative methods respect the constructivist understanding that knowledge is being co-created between myself and the students in our interactions (Bierema, 2002; Merriam, 2002) both in the classroom and in the research process. Qualitative Methods also recognize the researcher is the primary instrument in the study (Merriam, 2009). Interviews with students allowed me to understand their perspective on how the class worked and what meaning they made of their experiences (Merriam, 2009). This offered a more nuanced understanding of the course dynamics than can be found by analyzing public communications on a discussion board. Further, as recommended by Shea et al. (2010), this approach takes into account the entire course interactions, not just the postings on the main discussion threads. Finally, qualitative methods are suited to feminist inquiry because they take seriously the participants' own meaning-making, treating it as central data for the study (Merriam, 2009).

\section{A. Research Questions}

The research questions for this study were:

- What constitutes a social environment of safety in online learning community composed of multinational, multiethnic, and multigenerational students?

- What techniques used by the instructor are effective in creating a social environment of safety in online learning community composed of multinational, multiethnic and multigenerational students? What is ineffective?

- What is the role of culture in the online learning environment?

\section{B. Data Collection and Analysis}

The first source of data was my researcher's log. Although a journal is typically thought of as part of the audit trail supporting a study's validity (Merriam, 2002), in this case I used my journal as a primary data source. It resembles field notes kept as part of an ethnographic study (LeCompte \& Preissle, 1993). I kept a running log all semester of the deliberate moves I made which were intended to create a supportive social context for learning in the online class. I also noted points of concern or conflict that arose, as well as jotting down questions I had about the progress of the course. By comparing my journal with student's perceptions of the class dynamics, I hoped to gain an understanding of the efficacy of various efforts to create a social context for learning with a diverse group of learners.

The second source of data was a series of interviews conducted over a period of four weeks after the course was finished and final grades submitted. I sent an email to all 16 students in the class, inviting them to participate in an interview with me to talk about their social experience in the class. The purpose of the interviews was to explore their perceptions of the climate and interactions in the classroom, seeking to understand the meaning they made of the class experience (Merriam, 2009). Eleven students expressed interest in talking with me. During the first two weeks in January, I conducted 30 to 40 minute interviews with six class members. One student, a second-language English speaker, asked if she could send me written responses since she wanted to participate but was concerned about the verbal interaction. She sent me two pages of comments in response to the interview protocol. I recorded and transcribed all of the interviews. Once the first six were transcribed, I loaded them, along with the written commentary from the seventh student and my researcher's log, into my data analysis software. I began the process of initial coding using constant comparative analysis (Butler-Kisber, 2010), seeking themes and patterns in the 
data. The seven student sources plus my journal soon showed some alignment between my intentions and student responses. However, as I continued coding and comparing data segments, I also noticed some variety in student perceptions, which is a common occurrence in qualitative research (Marshall \& Rossman, 2006). As a result, I emailed the remaining four students who had expressed willingness to talk with me but who had indicated they were not available until later. Three of them agreed to an interview, and in late January I conducted three more interviews of approximately 30 to 40 minutes, seeking further insight into the social environment of class.

With those interviews transcribed and uploaded to the program, I moved on to focused coding, seeking patterns or themes in the data. With the additional interviews some themes in the data became clearer, while new ones surfaced. Finally, using axial coding, I began to group the themes into categories of findings. In the findings all students are referred to by pseudonyms. Also, the majority of the students with non-Western names had chosen a Western name for themselves in class. In creating pseudonyms I have respected their tradition. Table 1 shows the demographic makeup of the participants.

Table 1. Participant Characteristics

\begin{tabular}{llll}
\hline Name & Born/Raised & Live/Work & Ethnicity \\
\hline Karen & Taiwan & Philippines, US & Taiwanese-American \\
Laura & Korea, US & Asia & Korean-American \\
Betty & US & Mexico & American-Mexican \\
Samantha & China & US & Chinese-American \\
Beth & US & US & African-American \\
John & US & US & Japanese-American \\
Peter & Asia, Australia & India/Singapore & Asian-Australian \\
Robert & Canada & Korea & Canadian \\
Steve & US & Global & White \\
Mike & Korea & US & Korean \\
Leanne & US & Europe & White \\
\hline
\end{tabular}

\section{FINDINGS}

\section{A. Safe Environment}

To answer the first question, what constitutes a social environment of safety in a multinational online course, findings suggest for some students an online class can offer a safe space to interact, and it may even have some advantages over a traditional face-to-face environment. Building confidence, creating space for each voice, and working with smaller groups were the primary methods of creating a safe classroom space.

\section{Building confidence}

A number of the students commented on their initial lack of confidence as a hindrance to safety in the classroom. Both Laura and Betty came in feeling anxious about the class. Both have family responsibilities and had been away from formal education for some time. Laura initially felt unsure of her academic abilities. She commented that the class felt safe because "I didn't ever feel that I was made to feel dumb, or stupid, or how come I didn't know that.” For her, being safe included a reduction of anxiety and encouragement that she could do the work. For Betty, it was important that the environment not pit the students against one another. She appreciated being "released from a competitive feeling” and instead 
learning to support and encourage one another. She thought that "if you feel safe, and if you feel you're in a warm nurturing type environment, that you can relax more and you're not so concerned about everything being judged harshly, but as friends working together, maybe.” For her, competition was a source of tension, but cooperation and encouragement created an environment for learning. Karen had a similar response. She had learned in a community college class that "if we are in a comfortable and accepting environment, we can learn better" and she found that true for this course.

The students used words like "affirmation" and "encouragement" to describe how they began to know the space was safe. Robert explained that "there was a definite effort to encourage each other and to affirm each other. And I think that was very positive." Karen added that "sometimes we feel dumb, because it's not easy to write" so the encouragement to "keep on, press on" was "very helpful." Betty commented "I liked the affirmation. I think that you're very affirming, and I think you set the stage for the rest of us.” In my instructor log in week five, I noted that "I continue to blend encouraging messages regarding their progress with pushes to improve." The student comments show that they noticed this strategy and responded positively to it.

\section{Voice}

An important aspect of a feminist classroom is voice, or the idea that each person has something valuable to contribute (Johnson-Bailey \& Lee, 2005; Tisdell, 1998). In setting up the class, I established the requirement that each student post their responses to the weekly questions, and then interact with three fellow-students. This approach is common in online classes and primarily serves as a learning strategy, but it also can serve to help each student develop voice since it requires participation. Several students recognized that the online environment supported development of voice. Robert commented that the students were encouraging each other, and that the online environment was conducive to positive interactions, perhaps more so than a traditional classroom. He reflected on a recent face-to-face class environment where "some people didn't participate quite as much . . . because of the fact that [other] people are more dominant." In contrast, he thought that the online participation was more balanced, "perhaps that might have been more possible with the online format than might have happened in class. I'm not sure if everybody would have always done that in a class setting." Peter agreed with that idea: "in an online forum we might have been able to say things we might not have said face to face. ... It forced us ... to think of an interaction because we have to post something." For him the requirement to post combined with the online environment created interaction that would not have occurred in person. As a bi-cultural person, with both Asian and Western backgrounds, he understood the different cultural dynamics clearly. He explained that in Asia students are not expected to speak up in class, but in Western classes participation is valued. So participation can be a difficult skill to learn. He commented, "I think Asians coming into our school environment for the first time have to take one or two years to learn that. And the online classes actually provide structure to do that." He saw that the online environment created a structure that supported the development of voice and confidence.

Online interaction supported another aspect of voice, as well, for the second-language participants. Mike described himself as "shy" which made it hard for him to participate, but he also commented on his "poor English listening skills.” Because everything was online, he could take time to look up words and think about his responses. He could also ask for more explanation when he did not understand something. So for him the online environment was beneficial to participation. Similarly, Samantha needed extra time to understand. She called it the "two-second processing delay" and explained that the online format gave that extra time she needed to interact. Peter, though not a second-language speaker himself, also commented on the benefit for Asians of having time to think through their responses. He explained that "learning to find your comments, process the composition and comments, and then post them, is like a safe environment . . . it gives a lot more processing time, but you're learning the flow." So for some second language speakers, the release from time constraints in the online class helped support their safety and their learning. 


\section{Groups}

A third aspect of safety described by the students had to do with groups. Realizing that 16 students were too many for productive discussion, after the first week's introductions I divided students into two groups of eight for the discussion threads. I maintained the same groupings throughout the course. Students appreciated being divided into smaller groups for the weekly discussions, and they appreciated receiving group feedback, especially when it was of a corrective nature.

Samantha explained, "I enjoyed the discussion forum has been resized into a smaller group, so that I would be able to focus and follow up each other's work closely." Robert thought the "group size was advantageous; it wasn't overwhelming that way and we got to know each other a little better." Karen said, "It's good that you divide in two" because at first it was too many people, but she "enjoyed them" when it was only eight. Peter agreed, saying, "At the beginning it was feeling unwieldy, to keep track of a large number of discussions, with the large class size. The smaller group was more intimate.” He said it enabled stimulating discussions while allowing him to keep track of them. No one really wanted a larger group. Laura expressed some dismay at losing the input of her other classmates. So I asked if she would rather have stayed all together, and her response was decided: "Oh, no! Because it was overwhelming at times for me, with . . . limited time to read all seven other posts and threads . . . . I think six to eight is a good number."

Interestingly, the second aspect of groups that made students feel safe was group feedback. In my log, I recorded that I struggled regarding how to give feedback so that individual students would not lose face or be shamed publicly. In week three I wrote, "I actually considered sending feedback individually by email so no one would be embarrassed. But then I decided this goes against the ethos of the class. Plus there were so many mistakes in common" that it made sense to correct publicly. The following week I described what happened:

This week I played around again with public correction. It's a mistake that a lot of students are likely to make, and frankly it's easier for me to point it out once than 16 separate times. So I worded it as "do you mind being our experiment" and pointed out what went wrong and how to fix it, after saying what went right. For the second mistake, I simply created an announcement and reminded everyone to do something different, and tried to make is slightly humorous.

As the description shows, I tried a two-part combination. First, I did give individual feedback publicly on the discussion threads to everyone. Second, for common, repeated mistakes I simply posted a correction to the entire class at once, rather than pointing out each individual's errors. Many of the students found this approach to be very helpful. Beth commented, "That was good. Totally do the same thing [in future] and it would help people.” Laura said, "I appreciated when you had the greater posts for the entire class. That was nice because we could learn from both groups." And Betty was very clear: "If you did give us a reprimand ... you gave a whole group reprimand. And so even a whole group reprimand makes people feel part of a group. Because we feel like we're the group." For her, group correction strengthened them feeling "like a team" and did not "cause people to compete." That was a significant part of the safety for her.

\section{B. Instructor Techniques}

In answer to the second question regarding techniques an instructor can use to create a social environment of safety, the findings suggest two primary categories of actions that I as the instructor did which were effective in establishing a social context for learning in an online class. The first category relates to things I did to set up the course and launch it in the early weeks of the semester. The second category relates to ways I interacted with students during the course of the semester. Interestingly, these two functions closely resemble Anderson et al.'s (2001) other two aspects of teaching presence: designing the course and serving as a subject matter expert. I will return to this point after describing the various techniques that the students found helpful. 


\section{Setting up the course}

The very first set of readings I gave for the class in the first week included a rubric for online discussions and a link to a web page about Netiquette. The rubric laid out expectations that posts would be scholarly, reply to and build upon one another's ideas, and show respect and sensitivity in all interactions. The netiquette link laid out similar expectations in more detail, describing explicit guidelines for helpful and ethical online behavior. Of course, this approach to discussion threads is quite Western, but making expectations explicit at the start is one recommendation for successful online interaction in international courses (Sadykova \& Dautermann, 2009). Five of the students mentioned those early readings as useful for setting up the tone of the class. For example, Beth said, "What was great about the whole program was you gave us the netiquette portion." Robert explained, "The outline . . . from the very beginning is that we're learning together. There is respect that should be part of our whole approach. ... So that just set the tone right from the beginning." Laura explained that the "initial readings kind of set up the social environment... [they] really enhanced the connection.” Betty thought it kept them from commenting incorrectly:

I think it was very good, right before we started posting you had us read an etiquette article, and that was really good because it gave us some guidelines. And again I think that also kept us from coming across too competitively or aggressively.

Mike also expressed appreciation: "You taught us etiquette for the online discussion. That was very helpful.” Clear expectations and guidelines seemed to promote a good atmosphere.

\section{Introductions}

That first week of class I also invited every student to introduce themselves and upload a photo. I started by introducing myself with a short biography and a picture. As each student posted an introduction, I responded that I was looking forward to learning with them this semester. In my log I recorded that “modeling appropriate responses by responding personally to every student's introduction” was a strategy that I used in setting up the course. In the interviews six students commented on the significance of those introductions and photos to help them get to know their fellow classmates. For example, Mike commented that "in the first class, you let us introduce ourselves with picture. That was very helpful for us to know each other and to remember." But not everyone did remember. In the interview, Peter said: "I've never even seen the photos of any of these people. So I don't actually know what they look like... Maybe that's something that could be done in the first week. And I can't remember whether we did that." When I reminded him that we did indeed do that, he was surprised; he had completely forgotten. So it did not help him any. But another student, Laura, who was also having trouble remembering, said that she "took screen shots of what everybody wrote of their personal introductions, and in the early weeks I did refer back to that a few times." She wanted to remember the others and found a way. Karen noted that she found it helpful that I also introduced myself to the class. "I think first you introduced yourself to us" she commented. "And also the beginning, you [get] us to introduce ourselves, and also the picture, so we get to know each other" she added.

\section{Dedicated social space}

The third strategy I used in setting up the course was to create a space called the water cooler for social interactions. I encouraged students to use this space to post anything not directly related to course content, and I launched the thread with some humor about doctoral students as well as a discussion about managing studies and life. Students used the space for several different kinds of topics. Six students specifically named the water cooler as something that helped them feel socially connected to the class. Robert liked that they could use the water cooler "if we had secondary issues." Karen said "we can have something that is not related to the assignment . . . and I find that is very helpful. That's very good." Laura commented that "it was excellent to enhance the non-academic side." Betty recalled a specific incident where "one person-he was really suffering because of the loss one of the colleague's children, and I think it was a very painful time for him. And . . . it kept it from being too academic in a way.” They 
liked having a space to post things they found useful and thought others would appreciate. But two students also thought it was insufficient. Peter thought people did not really use it enough. He said, "Even at the water cooler I didn't see other people saying, oh, tell me a little bit about yourself." And Mike wanted it to have a more spiritual focus where students could pray for each other. He said this would help them "have more strong relationship." So the water cooler was useful, but less so for some students.

\section{Instructor interaction}

The second aspect of the class that every participant mentioned was their interactions with me. They commented on my interactions on the discussion boards, my feedback on their work, and my personal interactions with them by phone and email outside of the official class setting. They noticed how I interacted with them on the discussion boards. Steve commented that "when responses became [superficial], you pushed us all a bit—be specific, be academic. I think those were important." Betty noticed something similar, explaining that "you did give some personal comments when we started to go off on the wrong track." She also commented that she looked to me as a model for how to post: "I know for sure that I watched your... comments because they were a model for me.” Beth described my presence as "your leadership. You were always there. So if there was a problem or concern, someone else had already asked the same question and you had already responded. So...your presence was important to me as a student." Samantha expressed something similar: "my professor...is actively involved in the class and very quick to answer our questions." John also appreciated my involvement in the discussion board, saying "As we're interacting, it's good to hear from you. Sometimes I wonder are we on the right track, are we doing this right? So I thought that that was good.” The students appreciated my visible presence on the discussion board.

\section{Feedback}

Specific individual feedback on course work was found to be important to each student. Karen appreciated that I was "friendly, and give us feedback, and also write emails every week giving us information and greeting us. That is really helpful and kind of friendly, encouraging me to keep on." Peter liked that "your comments on our work were very detailed. . . In this subject, more feedback is better, and detailed feedback is even better." Another student emailed me at the end of the class, saying:

I have really enjoyed what is probably going to be my only on-line course, thanks to you. I've appreciated your guidance and input through the course and have learnt a lot from interactions with you. Thanks also for the effort you put in to give us such detailed feed-back, which has been particularly helpful.

Towards the end of the course, I decided to try a new approach to giving feedback. They were beginning to post early drafts of their final paper for feedback from me and their peers. One group spontaneously posted their drafts directly into the threads, rather than uploading attachments. I wrote in my log:

In one group, they posted their drafts in the discussion blocks, and in the other they posted attachments. So in the first group I gave interlinear comments in red directly in the discussion boxes. This made it REALLY easy for everyone to see what critique I was giving. The feedback was very positive. They liked seeing their own feedback this way and they liked seeing each other's drafts. They found it easy and clear.

In the interviews a number of students commented on how much they liked that particular form of feedback. Beth really liked it; she said, "So your feedback, if you do this again, don't change that. That was phenomenal. When you finally put it in red, it was like, wow!” Betty also really liked it. She talked about "the first week you added comments in red directly to our homework. I, and many others, felt that this was very helpful. Several students commented favorably online about this kind of feedback." She is correct; the online responses to the interlinear red feedback were overwhelmingly positive. The following week, our online platform was updated and I could no longer give interlinear feedback effectively, and the group was quite disappointed. While I provided feedback within their word documents, students did not feel it had the same effect as when they saw it right in-line in the discussion thread. 
Another issue was ineffective or harsh feedback. Beth was frustrated because she felt she did not get good peer feedback. She said, "The feedback to me was so superficial, and I felt like I was always giving but not getting." She also noticed that some students gave inappropriate feedback, which she explained: "they were very highly critical, so I did see that. As if they were the professor." Betty experienced this too. She said, "one student used the marking tool on Word, corrected my paper, and I felt like he was my professor." She also noticed harsh feedback from one student to another. In this case, she added, "You interceded and softened it for the person who was receiving it, I think, but also kind of stopped that kind of aggressive [feedback]. I felt like it was a little aggressive.”

Finally, some of them noticed that I waited a little bit before engaging with their posts. Betty said, "You gave the question, or the comment, and then you waited...a little bit to let people post...and then you gave some general pluses, and some individual positive remarks to kind of sum up." She liked the summing up because it helped her know what was important, and also let her know that it was okay to move on to the next topic. Mike also liked that I gave them time to interact first, and then added my feedback. He explained:

You let us give comment [to] each other at least three times a week. Through the feedback we could be interested in each other and take care of each other and encourage each other. ... And you gave comments to us the end of week. Very good strategy because if you had given us comments the earlier week, we could not have given comments each other.

He was right, because I deliberately waited until late in the discussion period to give feedback, thinking that for some students, once I as the instructor/expert spoke, they would not say more. Mike's comments supported that thinking.

\section{Individual communication}

In the log I also recorded having "personal communication by email and phone, as needed with individual students requesting extra support and input.” There were multiple journal entries regarding personal communication, most of them positive but a few of them more challenging. Every participant mentioned their appreciation of this interaction. For example, Peter explained:

I was able to just even comment on my own personal sense of I'm not a very good proofreader. And you did suggest, you know, maybe one option is to pay for a proper proofreading right at the end of your dissertation. And you explored things that were more for life process, rather than just academic process. So I appreciated those little dialogues that we had, even though they were just one or two lines sometimes.

He talked further about the benefit of personal communication, remembering a discussion I initiated with him about his academic goals.

I did appreciate at one stage you [asked about my academic goals]. And that generated a few emails and included the program chair. I felt as if you cared for me and my academic world and my personal world more than just, let's get this subject done. And I did appreciate what I felt was going beyond the call of duty.

I also had some dialogues with Samantha on her study, and she wrote "I enjoyed the professor would be able to participate with each one of the student [sic]." Karen too found it helpful, saying "I appreciate that you give me time and you return my emails promptly, and I think you are open and welcoming to ask a question.” Steve also appreciated the extra personal communications. He said, "you and I have talked on the phone or even through email interaction somewhat" and he liked that better than purely course communication. He also liked the invitation to participate in the study, saying, "I think an exit interview is positive.” Laura was particularly enthusiastic in her comments, saying:

Oh! I appreciated the one to one emails, like you were giving us personal attention and care. Yes, we were part of the group online, but I felt like you were giving me personal care when I sent an email directly to your school address and then you responded back to my school address outside of the threads for everybody. That was very, very nice! I felt it was almost one to one teacher 
interaction. That was helpful. I would suggest continue doing that. I know it's more work for you but I appreciated that.

Personal communication was also important when difficulties arose in the course. One student made a post that could be read as racist. I emailed John, who received the comment, and asked what he thought. I emailed Steve, who made the post, and pointed out how it could be understood as racist. In the interviews, I asked each student to reflect on the experience. John saw my interactions as a "good balance of the intercultural, the cross-cultural component... and then if I could use this term, critical consciousness." He did perceive the post as being micro-aggressive and appreciated my intervention, saying, "I thought it was quite thoughtful and sensitive actually. In other words, you were the one that was proactive in asking me how did I feel about that, because that doesn't always happen.” Steve also was thankful: “As I re-read my actual responses...I can definitely see how this could be misunderstood. So I thought you did a good job there and I was appreciative, and thankful that I got a chance to respond.” Careful use of personal communication helped correct a misunderstanding in the class.

\section{Hindrances to Online Learning}

Of course, not all students liked the online venue. Two in particular were fairly strong in expressing their overall dislike of online learning. For one student, Beth, the entire experience was fairly negative. When I asked about the class, her reply was an emphatic, "I hated it to no end!" She was frustrated by the superficial feedback she received from her peers on her work, was frustrated by the poor English skills and lack of confidence of some students, and was keenly aware of gender and race power issues she saw play out in the environment. Another student, Steve, was seriously frustrated by the lack of personal interaction in the course. He said, "The social aspect for me was a downer." The main problem was the misunderstanding he had with John, and he found that challenging to work out in the online framework. He was sure that it would have never happened face to face, because personal conversation would have allowed for immediate clarification and correction. That incident, coupled with his strong desire for visual and verbal communication, seriously affected his feelings about the class. Both students recognized that they had made some academic progress, but neither would be likely to take an online course if they had other options available. Although both students were able to name specific aspects of the course they found beneficial, overall they did not enjoy the experience.

\section{Desire for face to face contact}

Every student in the study wished for face-to-face contact. A few of the students had access to the university's campus and were able to attend two library training workshops that were offered during the semester. The sessions were taped and uploaded, but those who attended in person felt they gained most from the sessions. Mike said, "That was special time, just one and a half hours, but through the class we had very good relationship [sic] with each other." He explained, "To have good deep relationships, you need to meet face to face." A few students were able to see me face to face as well, and they expressed appreciation for that. John realized it helped him, saying:

It was a real benefit to me, to come to your office and interact the way we did. It just helped get me on a good track, on a good path. So in that regard I was at an advantage being on campus.

Betty remembered a personal conversation we had right at the start of the semester: "When you told me that you had also gone back to school when your kids were older and it can be done! Because I looked around at all these young students, and I'm thinking, what have I done!” That conversation in week one reassured her. Karen did not initially realize it was okay to visit my office since the class was online. But Betty mentioned having seen me, and Karen decided to come as well. In the interview she explained:

In the middle I learned that I can ask you. I learned from Betty that...she can make appointment with you and ask you questions, so oh, okay, I can do that. Because I thought it was an online class and I didn't feel comfortable to ask. 


\section{Lack of face to face contact hinders learning}

Those who did not have face-to-face contact with me and the other students lamented that fact. Laura explained, "I...just wish I could have run over to meet people face to face for two-way dialogue, just to ask for clarification or for two way dialogue to happen, so that was a little frustrating at times." John explained, "The distance of not knowing people personally was a little bit of a challenge.” Robert thought he had better interactions with the two students he had met face to face in a previous course: "I knew a couple of the people already. . .so interacting with them would probably be on a little deeper level." Peter agreed:

In the online courses the ones who I know from the extension center, I felt much more ease in communicating. Those would be the ones that, quite often, I'll comment on their papers first. There was a sense that I would know how they will react, even if I say something which is not positively constructive, but may come across as negative, I know the person and I know they'll take it okay because we have a relationship.

Steve and Beth, who expressed the most dislike of the class, both thought the online format was a hindrance to their learning. Steve would have preferred personal contact, saying, "I like the face to face, I like facial expression and dialogue that takes place, learning within a social environment where you see and hear the auditory aspects and visual aspects." Beth too commented, "If we could have met first, in the classroom, to see everyone, get understanding, hear their voices, it would have been probably easier for me as well."

\section{The Role of Culture}

To answer the third question, what role does culture play in creating an online learning community, the findings show that acknowledging and discussing the different cultural perspectives contributes to the learning climate, but does not completely overcome potential challenges. Most of the participants in the study discussed the role that culture had played in our online interactions. They saw both benefits and drawbacks. John thought the variety added depth, saying, "I thought it was interesting hearing people reference their experience as they thought through the questions and so forth." Samantha said something similar: "My classmates have various background, their opinions, life philosophies and their depth of knowledge are something they brought into this class." But she went on to say that she "felt I lacked" when her classmates discussed things outside her personal experience. Betty said that initially it affected how she communicated, explaining, "I think at the beginning, because we were from various cultural backgrounds, I felt like I needed to be cautious in how direct I was.” She went on, "I didn't know how fragile people would be...but I think that will happen any time you get into a multicultural situation." She was aware, but also thought it was normal. Laura appreciated the more Western approach, saying:

I came away feeling more equipped but positively, not in the Asian context where if you don't get it right the first time then why don't you have it done, and I'm going to give you a bad grade, that kind of a situation. So it was fun to learn together!

This particular class was primarily an Asian and Western group. So a significant amount of reflection involved contrasting those two ways of thinking and approaching the course. In my log I recorded that early in the semester we had a discussion regarding disagreement. "Western/US students want disagreement and push-back, so they can hear a new perspective and learn from it. Asian students are uncomfortable with open disagreement and prefer to express agreement. There has to be a way to disagree in Asia, but what is it and how can it apply to this course?" We worked quite a bit on the concept of critical review of publications and peer writings. Karen felt she made progress in her thinking.

[For] the Asian, it's sometimes difficult to distinguish-to separate-people and things. And so sometime I hesitated to give my feedback...but later I learned that critical thinking doesn't mean to say negative thing, that you don't write well, or something like that. But to train myself to see this is a good one, and that isn't, but I can express my opinion. And that's kind of training to help me to see, oh, this is okay, I need to learn to be critical. Critical doesn't mean negative. That was 
very helpful.

Peter also talked about this concept at length. As an Asian-Australian he bridged the divide and was able to see from both perspectives. Speaking of another Asian student, he said, "Take this as an observation," and explained:

He was very cautious in his interactions in the classroom, especially in the beginning. The whole thing of Asians speaking up in the large classroom-they're a bit more hesitant. I think the online class has really helped him get used to what this interaction is all about. Because we've just finished a subject in the extension center, and it's the most I've seen him interact in class, ever.

Peter thought perhaps the online class helped the Asian students increase their participation.

Finally a couple of participants thought the combination of online and cultural differences was a hindrance. Steve thought being online might hamper Asian students, commenting, "I find that within an Asian context, when an Asian student struggles, they would have a lot of trouble with not wanting criticism, and facial expression was really important in communicating with each other. So I think that would be a challenge in the online learning environment." And Beth thought the cultural challenges hindered the online learning.

Culture played a huge role and the passivity of the feedback, of the self-confidence. Gender played a role in it, a huge role. .. . Cultural differences, male dominating female, was huge in this class. And it made me sick to my stomach. Second language, same thing. I think some of us may have thought less of those with that language barrier. Also, that language barrier played a role... in feedback.

For Beth, the issues that came with cultural and linguistic and gender differences hindered rather than helped her learning. All of the participants noticed the cultural differences, and most of them were willing to discuss them. But for some of them, the challenges seemed to present significant levels of stress that hindered their learning.

\section{DISCUSSION AND RECOMMENDATIONS}

The purpose of this study was to examine my own efforts to co-create a social context in an online classroom that is welcoming and supportive to a diverse student population enrolled in a graduate research methods course. I wanted to discover what a safe space looked like in that context, what instructor techniques were effective in building an online social community and what role culture played in the social environment. Early literature suggested teaching presence included setting up the course, facilitating the social environment, and the instructor serving as subject matter expert (Anderson, et al., 2001). Later reviews added a fourth aspect, assessment. The findings from this study support the four categories, and suggest a few specific factors that may be of particular importance in a multicultural online class (Akyol \& Garrison, 2008).

First, the findings show that social context is in fact inseparable from the broader construct of teaching presence. While coding the interviews, I wrote several memos about how interesting it was that students seemed unable to separate the academic and social aspects of the course. I would ask a question about the social environment, and students would respond with comments about the academic work. Karen stated it quite clearly: "the social is also related to class as well." For them, the course organization, the conversations, the instruction, and the feedback were inseparable, and together built the concept of a safe space. The kind of instruction I gave and the way I gave feedback were equally as important as the overtly social things like introductions and the water cooler space. In the end, the students told me that all four strands were vital. Without good course design, and content expertise, and supportive feedback, the social environment would fail to materialize (Akyol \& Garrison, 2008).

Second, the findings suggest that the online environment may be useful for students who are reluctant to 
speak up, initially lack confidence, or are working in a second language. The actual structure of requiring everyone to participate regularly seemed beneficial for this group of students. They knew participation was expected and counted toward their grade, and so they consistently engaged in discussions. Receiving positive feedback from me and from their peers enabled them to keep trying, and to slowly develop confidence. The asynchronous nature of the class allowed for time to think and to construct responses, which was beneficial for the less confident as well as those working in a second language. They could take time to process, think, and polish their responses before posting them online. This aligns with the findings of Gunn, McSporran, Macleod, and French (2003) that shy students can benefit from the online format, and that discussion boards with posting requirements can help build student confidence.

Third, findings from this group suggest that building in an opportunity for initial face-to-face contact might enhance learning in a multicultural online course. Students who did have an opportunity to meet me or some of their fellow-students invariably thought this helped them with the class content. The two students who struggled most with the course thought face-to-face contact would have significantly improved their experience. If it were feasible to launch a class with a short, intensive time together, learning might be enhanced, as Morse (2003) found to be true with his study of high context, primarily Asian students. Alternatively, phone calls, Skype calls, or even videos posted online might help with this aspect of the course. However, not all students have access to high quality networks, so feasibility would need to be studied carefully before adding certain elements to a class (Rogers, et al., 2007).

Finally, the findings suggest that the online class can work well with a multicultural student population, but it may require some extra care and attention on the part of the instructor. Being willing to surface and discuss an area of challenge seemed helpful. Sadykova and Dautermann (2009) recognize this dynamic, saying "cultural and individual differences are not only acknowledged but also become a matter of exploration and pride" (p. 102) Early on we talked about needing to express disagreement in the form of constructive criticism. Repeatedly through the early weeks, I modeled this for the class. I also encouraged students who were simply posting positive responses to the readings to offer some critique as well, and gave them examples of what they could say. This type of formative assessment requires time and detailed involvement by the instructor, and seemed to show positive results. Some of them, like Karen, learned easily, while others struggled more, but all students made some progress in learning to critically evaluate the work they were reading, which is considered an essential skill in a Western doctoral program. Interaction between the instructor and the students also played a significant role in students' perceptions about this course. Both in terms of feedback online, and personal communication through email, phone, and office visits, the students needed to feel they could interact individually with me. Different students preferred different methods, as well. Steve liked phone calls so he could hear my voice. John and Karen took advantage of personal visits when they were on campus because they preferred oral communication. Laura liked personal emails because her phone and internet service were unreliable. Being accessible to them in the form they preferred added an extra dimension of strength to the class.

Like all studies, this one had limitations. The sample was small, and the findings may not necessarily resonate with other multicultural online communities. The fact that I as the professor conducted the study may have limited some student's responses, even though the class was over and grades had been submitted. Additionally, this group was primarily Asian and Western, so the findings might be different with other cultural groups. One aspect of diversity was absent from this group, as well. The school is a Christian one, so there was no religious diversity in the representation. Further study needs to be done with students from other cultural and religious backgrounds to see how well these findings apply, and what additional factors might contribute to a successful multicultural online learning community.

Overall, the results of the class were very positive. The students performed very well on their final summative assessments, and many of them expressed appreciation for what they had learned during the course. The online environment clearly has some challenges that are different from those of a face-to-face class, and adding multiple cultures and ages can increase the challenge. But the variety can also add to the depth and richness of the interactions, as a number of students mentioned in their comments. 


\section{CONCLUSION}

The benefits of online learning in terms of accessibility, and the opportunities in terms of globalization, seem clear. There is a growing need for adult educators to be competent cross-culturally in our teaching and research (Johnson-Bailey, Baumgartner, \& Bowles, 2010). However, our reach may currently extend beyond our theory, as western educators can now "teach" people from around the globe (Rogers, et al., 2007; Tollman, 2003) without having any clear sense of how multicultural, multiethnic, and multigenerational challenges impact our classrooms. This study offers a small insight into my attempts to be deliberate about my teaching presence, particularly in co-creating a social context where students feel safe, accepted, open, and willing to learn from me and from each other. 


\section{REFERENCES}

Akyol, Z., \& Garrison, D. R. (2008). The development of a community of inquiry over time in an online course: Understanding the progression and integration of social, cognitive and teaching presence. Journal of Asynchronous Learning Networks, 12(3-4), 3-22.

Anderson, T., Rourke, L., Garrison, D. R., \& Archer, W. (2001). Assessing teaching presence in a computer conferencing context. Journal of Asynchronous Learning Networks, 5(2), 1-17.

Archer, W., \& Garrison, D. R. (2010). Distance education in the age of the internet. In C. E. Kasworm, A. D. Rose \& J. M. Ross-Gordon (Eds.), Handbook of adult and continuing education (pp. 317-326). Los Angeles, CA: Sage Publications, Inc.

Bierema, L. L. (2002). A feminist approach to hrd research. Human Resource Development Review, 1(2), 244-268.

Butler-Kisber, L. (2010). Qualitative inquiry: Thematic, narrative, and arts-informed perspectives. Los Angeles, CA: Sage Publications Inc.

Cannon, L. W. (1990). Fostering positive race, class, and gender dynamics in the classroom. Women's Studies Quarterly, 18(1/2), 126-134.

Chick, N., \& Hassel, H. (2009). “Don't hate me because I'm virtual”: Feminist pedagogy in the online classroom. Feminist Teacher, 19(3), 195-215.

Gunn, C., McSporran, M., Macleod, H., \& French, S. (2003). Dominant or different? Gender issues in computer supported learning. Journal of Asynchronous Learning Networks, 7(1), 14-30.

Johnson-Bailey, J., Baumgartner, L. M., \& Bowles, T. A. (2010). Social justice in adult and continuing education: Laboring in the fields of reality and hope. In C. E. Kasworm, A. D. Rose \& J. M. Ross-Gordon (Eds.), Handbook of adult and continuing education (pp. 339-349). Los Angeles, CA: Sage Publications, Inc.

Johnson-Bailey, J., \& Lee, M.-Y. (2005). Women of color in the academy: Where's our authority in the classroom? Feminist Teacher, 15(2), 111-122.

LeCompte, M. D., \& Preissle, J. (1993). Ethnography and qualitative design in educational research (2nd ed.). San Diego, CA: Academic Press, Inc.

Marshall, C., \& Rossman, G. B. (2006). Designing qualitative research (4th ed.). Thousand Oaks, CA: Sage Publications, Inc.

Merriam, S. B. (2009). Qualitative research: A guide to design and implementation. San Francisco, CA: Jossey-Bass.

Merriam, S. B. (2010). Globalization and the role of adult and continuing education. In C. E. Kasworm, A. D. Rose \& J. M. Ross-Gordon (Eds.), Handbook of adult and continuing education (pp. 401409). Los Angeles, CA: Sage Publications, Inc.

Merriam, S. B. (Ed.). (2002). Qualitative research in practice: Examples for discussion and analysis. San Francisco, CA: Jossey-Bass.

Morse, K. (2003). Does one size fit all? Exploring asynchronous learning in a multicultural environment. Journal of Asynchronous Learning Networks, 7(1), 37-55.

Rogers, P. C., Graham, C. R., \& Mayes, C. T. (2007). Cultural competence and instructional design: Exploration research into the delivery of online instruction cross-culturally. Educational Technology Research and Development, 55(2), 197-217. 
Sadykova, G., \& Dautermann, J. (2009). Crossing cultures and borders in international online distance higher education. Journal of Asynchronous Learning Networks, 13(2), 89-114.

Shea, P., Vickers, J., \& Hayes, S. (2010). Online instructional effort measured through the lens of teaching presence in the community of inquiry framework: A re-examination of measures and approach. International Review of Research in Open and Distance Learning, 11(3), 127-154.

Tisdell, E. J. (1998). Poststructural feminist pedagogies: The possibilities and limitations of feminist emancipatory adult learning theory and practice. Adult Education Quarterly, 48(3), 139-156.

Tollman, J. (2003). Classroom teaching in Botswana and online teaching from Georgia: Hard knocks and earned successes. Journal of Education for Library and Information Science, 44(1), 39-57. 